\title{
Cost Analysis of a Digital Health Care Model in Sweden
}

\author{
Björn Ekman ${ }^{1}$
}

Published online: 22 September 2017

(C) The Author(s) 2017. This article is an open access publication

\begin{abstract}
Background Digital technologies in health care are expected to increase in scope and to affect ever more parts of the health care system. It is important to enhance the knowledge of whether new digital methods and innovations provide value for money compared with traditional models of care.

Objective The objective of the study was to evaluate whether a digital health care model for primary care is a less costly alternative compared with traditional in-office primary care in Sweden.

Methods Cost data for the two care models were collected and analyzed to obtain a measure in local currency per care contact.

Results The comparison showed that the total economic cost of a digital consultation is 1960 Swedish krona (SEK) $($ SEK100 = US\$11.29; February 2017) compared with SEK3348 for a traditional consultation at a health care clinic. Cost differences arose on both the provider side and on the user side.

Conclusion The digital health care model may be a less costly alternative to the traditional health care model. Depending on the rate of digital substitution, gross economic cost savings of between SEK1 billion and SEK10 billion per year could be realized if more digital consultations were made. Further studies are needed to validate the findings, assess the types of care most suitable for digital care, and also to obtain various quality-adjusted outcome measures.
\end{abstract}

Björn Ekman

bjorn.ekman@med.lu.se

1 Health Economics, Lund University, Jan Waldenströms Gata 35, CRC, 20502 Malmö, Sweden

\section{Key Points for Decision Makers}

The analysis shows that the digital model of care uses fewer resources compared with the traditional model of care in the Swedish setting. Cost advantages exist on both the user side and the payer side.

Incremental expansion of the digital model of care could lead to substantial reductions in spending.

Further analysis is needed to understand more complex benefits and the associated risks and potential downsides of these types of primary care.

\section{Introduction}

Under the concept of eHealth, a large number of different types of digital innovations for health and medical care are found, including those for diagnostics, information management, and communication. Development in the field of eHealth and related services is progressing rapidly and will most likely continue to affect current health care systems in various ways. In particular, these technical developments have led to a simultaneous increase in the expectation that they will lead to significant efficiency gains and reductions in overall health spending. In 2005, the RAND Corporation suggested that the introduction of health information technologies, such as electronic health records, could save the US health system around US $\$ 81$ billion per year in efficiency gains [1]. The study also identified additional 
cost savings twice as large from the broad introduction of health information technologies to prevent and manage chronic diseases in the USA. More recently, other stakeholders have made similar claims. For example, Goldman Sachs suggests that around US\$300 billion could be saved from such investments in the US health system [2].

In Europe, the European Commission and other organizations point to large expenditure savings from the introduction of various types of eHealth technologies [3]. Focusing on the Swedish health care system, McKinsey finds that savings of around 180 billion Swedish krona (SEK) (equivalent to approximately US\$20 billion as of February 2017) per year could be accomplished through the implementation of various types of eHealth solutions [4]. Similarly, PWC suggests that the Swedish health system could save around SEK1.2 billion (US\$136 million) per year if one in ten primary care visits is made over the Internet instead of at a traditional clinic [5].

However, the evidence base for these claims is relatively small and of varying quality and not many have analyzed the cost impacts in any systematic manner [6, 7]. One decade on from the RAND study, the significant efficiency gains from various types of eHealth technologies do not appear to have been realized [8, 9]. The reasons for these failings include weak uptake of and adaption to new technologies, poor design of innovations, and costly technologies in terms of purchase and maintenance.

While many digital solutions replace existing analog systems, one innovation with potentially large impacts on the health care system is the ability to provide services over the Internet. By means of telehealth, patients are able to consult with a health care provider without the need for and associated costs of an in-office visit. During a digital consultation, the patient describes his or her symptoms and the 'visit' results in one of several outcomes: no further measures; general or specific advice; prescription for medicine; referral to another provider, or further laboratory testing or scans. These outcomes overlap with most of those of an office-based primary care consultation. Given the high levels of over-utilization of hospital care partly driven by inaccessibility to primary care services, digital consultations could lead to improved access to certain services at lower unit costs [10].

The number of digital consultations that are currently taking place globally is unknown. In the USA, the market for telehealth reported sales of some US\$9.6 billion in 2015 and is expected to grow by $32 \%$ over the next few years [11]. The Veteran Affairs' telehealth program provided some 1.7 million telehealth episodes of care in 2013, a number expected to increase over the coming years [12]. In the UK, the government expects the number of people reached by telehealth services to exceed 3 million by 2020 [13]. In Sweden, estimates from such providers suggest that the number of digital consultations is around 60,000 to 80,000 per year (in a population of some 10 million people), mostly for primary care type of services. Also, the number of providers of digital health care services is increasing, and examples can be found in most European countries, North America, and some other regions [14, 15].

The digital health care model will most likely increase both in scale and scope over the coming years. More people will gain access to a digital health care provider, and more types of services, including specialized care, will be offered by this model of care. To make sound investments in health care, evidence is needed on the effects of new technologies, including their economic costs. The main purpose of this study is to contribute to the expanding body of evidence around the impacts of digital innovations in health care. In particular, it aims to evaluate the cost of a digital care model compared with that of the traditional (inoffice) way of providing primary care in Sweden. The perspective is that of the whole society, including the costs to both providers and users of the services. Based on the analysis, the study then simulates the impacts of incrementally scaling up the digital model by different rates of substitution.

\subsection{Primary Health Care in Sweden}

Health care in Sweden is the responsibility of regional governments (counties). There are 21 regions in Sweden that fund inpatient and outpatient care by means of general taxes, state grants, and user fees, the rates and levels of which vary across the regions [16]. The most common way of obtaining primary care is to make an office visit to a primary care clinic (in Swedish Vårdcentral). There are around 1150 such clinics throughout the country. On average, two-thirds are run by the regional health authorities directly and one-third are privately owned practices that contract with the regional authority. The primary care clinics differ in many ways from those in some other countries where such types of clinics are owned and run by single or multiple general practitioners (GPs). Most primary care clinics in Sweden are staffed by several different types of providers, including GPs (between four and six per clinic), nurses, and physiotherapists.

About 14.5 million primary care visits take place annually in Sweden, equivalent to 1.4 per person [17]. The total spending on primary care was around SEK28 billion (US\$9 billion) in 2015 [14]. Over past years, per capita spending on primary care has been increasing in constant terms, suggesting an underlying issue with cost pressure [16].

In addition, there is broad public and political concern over inadequate access to medical services, including primary care. Over the past decade or so, a number of reviews 
have pointed at issues with access to services, both with respect to unequal access across socioeconomic groups and across geographic areas $[16,18,19]$. Recent reforms have aimed at improving the general public's access to health care by, among other things, introducing enhanced patient choice and free provider establishment of primary care practices [20].

One underlying problem facing the Swedish primary care system, and one that it shares with most if not all other countries, is a shortage of human resources for health. The national government has set a target of around 1500 inhabitants per GP. However, the current number is over 2000, making it difficult for policy makers to reach set goals of access to services [13]. Determining the extent to which digital models of care can contribute to solving the challenges of access to health care services in Sweden and elsewhere will require further studies of their impacts, including those on costs.

\section{Materials and Methods}

\subsection{Cost Estimates}

The study estimates both the direct costs and the indirect costs for each of the two provider models as well as for the users of services.

\subsubsection{Provider Costs}

The direct provider costs include staff remuneration, lab costs, and diagnostic resources. The indirect costs include administration and support, management, office and equipment rent costs, and investment write-offs.

To assess the costs associated with the traditional model of care, the study made use of the most recent cost data published by the Swedish Association of Local Authorities and Regions (SKL; an umbrella organization for the regional health authorities). ${ }^{1}$ The name of the indicator is "costs per care contact in primary care: the costs of the counties per weighted care contact in primary care," which has been estimated for every county and region since 2008 . Specifically, the study used the national mean of these cost estimates for 2015, the most recent year available. While the SKL cautions against making detailed cost comparisons between the counties because of differences in reporting and measuring, the national average provides an estimate of the total provider costs of producing one unit of consultation in a traditional primary care clinic.

The direct and indirect cost data for the digital care model were obtained directly from the data base of the

\footnotetext{
${ }^{1}$ The data are publically available at http://www.vardenisiffror.se.
}

digital care provider, Min Doktor (http://www.mindoktor. se). Min Doktor started operations in 2014 and is still in a development phase where initial investment and development costs are relatively large. Research and development costs have therefore not been included as these types of resources are not used to run the model, nor are they included in the costs of the traditional care model. To obtain a representative estimate of the unit cost of care, it was decided to include the data for November 2016 based on the assumption that operations are moving toward their steady state under current investments. The cost data of the digital provider were compiled and divided by the number of consultations for that month to arrive at the unit cost of consultation.

\subsubsection{Patient Costs}

The direct and indirect resource usages to obtain a care consultation on the part of the patient were also collected. Direct costs include user fees [21], and indirect costs include time and travel costs. Adopting a human capital approach, the average monthly salary for a white collar employee was used as the basis for calculating the time costs of obtaining care for both models [22]. The time cost items include waiting time, travel time, and consultation time. The average time for a consultation was obtained from the literature [23]. The travel costs and travel times were estimated by making an assumption about the mean length of travel based on recent reviews [24]. As no reliable estimates for intangible costs (pain and discomfort of care) are available, no such costs have been included in the study. ${ }^{2}$ Similarly, no environmental impacts have been estimated.

\subsection{Methods}

The cost data were compiled and adjusted to a common denominator. In the case of time costs, the common denominator is set to $60 \mathrm{~min}$, i.e., hourly wage costs and travel and waiting times in hours. Estimating the waiting time for the traditional care model is difficult. SKL publishes the share of counties that live up to the national health care guarantee regulation. The regulation specifies, among other things, that a patient should obtain an appointment within 7 days. This implies that in reality the waiting time for an actual visit may be between a few minutes and several days. Regardless of the ability of providers to meet the care guarantee mandate, it is the time

\footnotetext{
${ }^{2}$ It may be assumed that there are aspects to this issue, such as the discomfort of having to travel, finding oneself in a place with other sick people, or the risk of infecting other persons while traveling and waiting.
} 
the person has to wait to obtain an appointment while not being able to do other productive work, i.e., the opportunity cost of waiting, that is the relevant cost measure in this case.

In addition to the waiting time to make the appointment, there is a waiting time at the clinic. It is not uncommon that patients have to wait quite a long time for their appointments as delays may have happened [25]. The current study assumes that the mean waiting time for a consultation is $30 \mathrm{~min}$ for both models [26]. For the traditional model of care, this is most likely a quite generous assumption, as waiting times may be significantly longer in many cases [27].

The mean treatment time for primary care in Sweden is $24 \mathrm{~min}$ [23]. The corresponding time for the digital care model is estimated at $15 \mathrm{~min}$, based on analysis of user data. Travel costs, both indirect and direct costs, have been set to zero for the digital care model and to $30 \mathrm{~min}$ and SEK100 (US\$11.29; February 2017), respectively, for the traditional care model [25]. The time costs have in both cases been multiplied by the average gross hourly wage for a white collar worker in the private sector.

Based on the results of the analysis, the study then estimates the financial (or provider budget) and the economic (or total societal) effects of scaling up the utilization of digital care using various substitution rates of $10-50 \%$. Given the nature of the benefits of the analysis and the aim to make a direct comparison between the two models, no discounting of resources or benefits have been made. Nor has the study made any estimates of quality differences between the two models of care. Finally, the study does not include any measure of the risk to patients (e.g., incorrect or delayed diagnosis) or to society (e.g., over-prescription of antibiotics) of either of the primary care models.

\section{Results}

\subsection{Cost Estimates for Provider Costs}

The national average cost per primary care consultation for the traditional model of care varied between SEK 2267 (US\$257) and SEK1387 (US\$157), with a national average of SEK1668 (US\$190) in 2015. Compared with the cost in 2008 , this represents an increase of around $28 \%$ in nominal terms. Generally, the costs were higher in counties with a relatively low population density in the north of the country (not shown).

The cost data of the digital care model are considerably more detailed than the aggregate data for the traditional providers (Table 1).

In November of 2016, the digital care provider had a total of 4063 consultations. The majority of cases were infections and skin conditions. Using the total number of consultations as the denominator, the total cost per consultation for the digital model is SEK961 (US\$109), 60\% of which is indirect costs in the form of administration and support staff, offices, equipment, and write-offs.

\subsection{Patient Resource Use}

Table 2 presents the direct and indirect costs for the users of primary care services for each of the models. The direct costs reflect the user fees of the two models. The price the patient pays for a digital consultation is SEK250 (US\$29), and the average price for the traditional consultation was SEK183 (US\$21; varying between SEK200 and SEK120) in 2016. These user fees are mostly paid out-of-pocket by the users. Children are exempted from paying for care in both models, and cost-ceilings are in effect for the elderly.

Indirect costs of care (time and travel costs) are significant, in particular for the traditional model of care. While both models have an assumed waiting time of $30 \mathrm{~min}$, this item constitutes half of total patient resource use in the digital model compared with around one-third in the traditional model. In contrast to the digital model, an in-office primary care visit also entails an estimated $30 \mathrm{~min}$ of travel time per visit.

\subsection{Total Costs per Consultation}

The total societal costs (provider and patient resource use) for the two primary care models are presented in Table 3. The total unit cost of care for the traditional model is SEK3348 (US\$380) compared with SEK1959 (US\$222) for the digital model, a difference of around $40 \%$. The table shows that the digital care model has cost advantages both for the provider and the user of services (around 51\% of the cost differences are found on the provider side).

From the user's perspective, the digital care model is almost half as costly as the traditional care model. The main difference is explained by the time costs associated with a consultation at the traditional primary care clinic. The only cost advantage for the traditional model is the direct patient costs in the form of user fees.

\subsection{Incremental Cost Impacts from Digital Substitution}

Based on the above calculations, this part of the analysis addresses the question of what would be the impact on the total societal and financial costs if the digital care model is scaled up to some reasonable share of the total number of primary care visits in Sweden. As noted earlier, there were around 14.5 million such visits in 2015 [17]. It would be unreasonable to assume that all primary care visits could be 
Table 1 Total cost per consultation, digital provider, November 2016. Source: digital care provider

\begin{tabular}{lcc}
\hline Category & $\begin{array}{c}\text { Value, } \\
\text { SEK }\end{array}$ & $\begin{array}{l}\text { Share } \\
(\%)\end{array}$ \\
\hline A. Direct costs & & \\
A.1 Remuneration, lab, and diagnostics & 385 & \\
Sub-total (A.1) & 385 & 40 \\
B. Indirect costs & & \\
B.1 Administration and support & 89 & 15 \\
B.2 Management & 114 & 20 \\
B.3 Office space & 36 & 6 \\
B.4 Equipment, operations and technical & 253 & 44 \\
development & & \\
B.5 Write-offs & 84 & 15 \\
Sub-total (B.1-B.5) & 576 & 60 \\
Total (A + B) & 961 & \\
\hline
\end{tabular}

SEK Swedish krona

replaced by a digital consultation. Assuming a substitution factor of 1.0 (i.e., no scale or price effects) and using the differences in the provider costs and the total unit costs, respectively, between the two models multiplied by some share of the total number of visits, Fig. 1 shows the effects of scaling up the digital care model to $10-50 \%$ of total visits.

The estimations show that if $10 \%$ of the primary care visits made today at traditional clinics were instead conducted digitally, the gross financial savings would be around SEK1 billion (US\$114 million). The total societal cost savings would be around SEK2 billion (US\$229 million). If the degree of substitution were $50 \%$, these savings would be around SEK5 billion (US\$565 million) and SEK9.9 billion (US\$1313 million), respectively.

However, the total cost impacts also depend on the substitution factor, i.e., the ratio of traditional to digital provider costs. Even at the high end of the above simulations, this factor would need to be as high as 2.4 or higher to lead to an increase in total spending on primary care as a result of introducing the digital model of care.

The results are sensitive to some of the underlying cost estimates. In particular, the indirect user costs make up half of overall cost differences (Table 3). Reducing the estimated travel time for an in-office visit by $50 \%$ (from
Table 2 Patient costs, digital and traditional care model, SEK. Source: http://www.skl.se; http://www.scb.se/sv_/ Hittastatistik/Lonedatabasen/
Table 3 Total societal costs per consultation, digital and traditional care models, SEK. Source: Min Doktor, SKL; own calculations

\begin{tabular}{lllll}
\hline Categories & Digital model (DM) & Share, \% (DM) & In-office model (VC) & Share, \% (VC) \\
\hline A. Direct costs & & & & 11 \\
A.1 User fee & 250 & 25 & 183 & \\
Sub-total (A) & 250 & & 183 & 30 \\
B. Indirect costs & & & & 24 \\
B.1 Waiting time & 499 & 50 & 499 & 30 \\
B.2 Treatment times & 249 & 25 & 399 & 6 \\
B.3 Travel time & 0 & 0 & 499 & \\
B.4 Travel costs & 0 & 0 & 100 & \\
Sub-total (B) & 748 & & 1497 & 1680 \\
Total (A + B) & 998 & &
\end{tabular}

$D M$ digital model, SEK Swedish krona, $V C$ traditional model

\begin{tabular}{llll}
\hline Categories & Digital model (DM) & In-office model (VC) & Difference (VC - DM) \\
\hline A. Costs, providers & & & a \\
$\quad$ Indirect costs & 576 & a & a \\
Direct costs & 385 & a & 707 \\
Sub-total (A.1 + A.2) & 961 & 1668 & 748 \\
B. Costs, users & & & -67 \\
B.1 Indirect costs & 748 & 1497 & 681 \\
B.2 Direct costs & 250 & 183 & 1388 \\
Sub-total (B.1 + B.2) & 998 & 1680 & \\
Total (A + B) & 1959 & 3348 &
\end{tabular}

$D M$ digital model, SEK Swedish krona, $V C$ traditional model

${ }^{\text {a}}$ Not available data 
Fig. 1 Cost savings at different levels of digital substitution of primary care [Swedish krona (SEK) million]. Source: SKL's activity report for 2015; own calculations

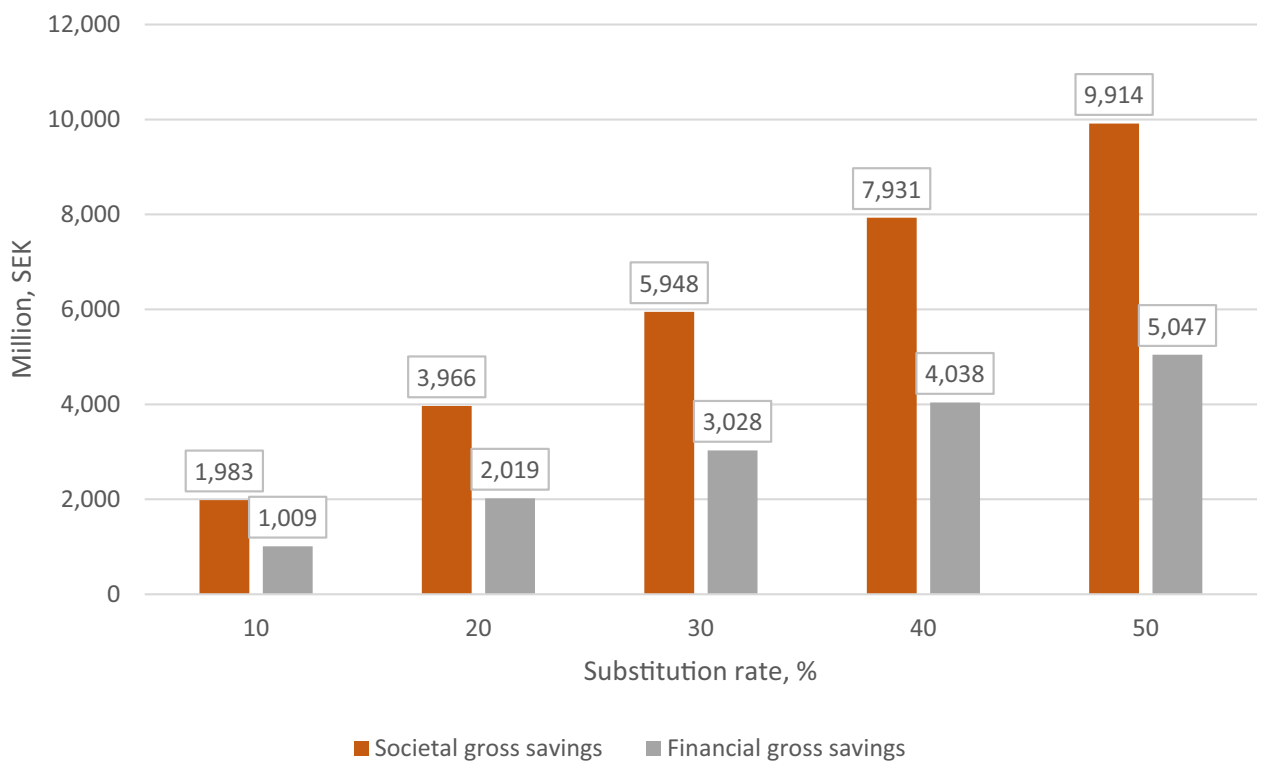

$30 \mathrm{~min}$ to $15 \mathrm{~min}$ ) reduces the total cost difference by $18 \%$ (not shown). Consequently, the substitution factor becomes 1.58 compared with 1.7. A similar sensitivity analysis on the provider side is difficult to make due to the unavailability of detailed cost data for the traditional model of care.

\section{Discussion}

This study contributes to the growing body of work aiming to understand the costs and effects of digital health care. Based on the currently available data on digital care and traditional primary care in Sweden, the analysis shows that the digital model has significant cost advantages. These advantages can be seen both on the provider side and on the patient side. In addition, based on the results of the analysis, the study also shows the financial and economic gross cost savings that could be realized if the digital care model is allowed to substitute for the traditional care model at various rates of digital substitution.

These results are in line with one recent study that measured the travel and environmental cost savings from one telehealth program in the USA [28]. Dullet et al. [28] found that the telehealth consultations during the study period led to total cost savings of US\$156 (SEK1375) per consultation compared with in-person care of a similar nature. The current study did not make any assessment of the environmental effects of the digital care model. To the extent that such a model of care reduces the amount of vehicle-based transportations and associated emissions of green-house gases, that impact should be added to the effects found here. As noted above, the costs of care reported by the Swedish county councils are higher in geographically large regions with relatively small populations. It is reasonable to assume that the patient costs in the form of time and transportation are also higher in these regions. The implication is that the digital care model may have a particularly large cost advantage in those parts of the country where physical distance may pose an obstacle for the delivery of care [29].

The results of this analysis are also in line with those of another recent study that analyzed the costs and the consequences of telehealth services for acute respiratory infections in the USA [30]. The authors found that the perepisode cost of care was half of that of physician office visits (and less than 5\% of emergency department visits). The study also found that around $12 \%$ of the digital consultations replaced physical visits. However, they also conclude that the majority of the digital episodes of care represented new utilization of services, leading to an overall increase in spending on these types of infections. This is an important finding that the present study is unable to address directly due to data unavailability. The findings from the current study suggest, however, that under observed cost differences the substitution factor would need to be above 1.7 to lead to an increase in overall primary care spending.

It should be noted that the issue is a complicated one as new utilization of services, as opposed to substitution, may, for various reasons, represent previously unmet needs that are now being met through digital care. As noted above, Sweden has a broadly acknowledged issue with access to primary care services. Expansion of digital care may be an efficient part of a solution to those challenges, if the services can be effectively regulated to avoid excessive use of primary care services of either model. 


\subsection{Limitations}

The findings of the study need to be interpreted with care for several reasons. First, the data used to estimate the costs of care for the traditional care model may contain costs for care that might not be relevant in this case [31]. With respect to the digital care model, it is currently in its start-up phase, with large initial investment costs. This aspect has been taken into account in the analysis by not including such types of costs in the estimations. As the model expands, the fixed costs will be spread out over a larger number of clients, which will reduce the unit costs (provided that the moveable costs do not increase), and the cost profile of this model will likely change with time. Also, the study makes use of the most recently available data: 2015 for the traditional model and late 2016 for the digital model. As noted above, a lower unit cost may in turn lead to an increase in demand if the cost reduction is also reflected in the price, leading to an overall spending increase. In addition, the human capital approach adopted in the estimation of time costs needs to be considered when interpreting results. To limit any risk of bias, the study adopts the same approach to both models of care.

Even if the outcome measure has been standardized to one consultation, a more detailed analysis needs to consider different types of contacts (e.g., contact with a physician or a nurse) and different types of care (counseling, treatment, and examination) to obtain a reasonable comparison. It would also be necessary to assess any types of risks involved with either of the models and to obtain some form of quality-adjusted outcome measure, including patientreported outcome measures. Moreover, the patient mix has not been explicitly incorporated into the analysis. While the digital provider receives patients from the general population (60\% women; mean age 37 years, minimum 2, maximum 94), it may be argued that the traditional model of care receives a larger share of elderly and patients in worse health compared with the digital model.

The evaluation has not considered all possible costs and consequences that may be associated with a primary care visit. As noted above, it may be assumed that there are significant cost savings to be made by 'visiting' a digital provider (or not having to visit a physical clinic) in the form of less discomfort and infection risk. These cost savings (or negative costs) would be over and above the time costs that the analysis has included. Finally, the static nature of the simulation presented in Sect. 3.4 needs to be considered as production and market structures may lead to significant dynamic effects, in turn affecting quantities and costs.

\subsection{Conclusions}

Based on the above analysis and discussion, the following main conclusions are drawn. The digital care model may be a less costly alternative to the traditional, office-based primary care model in the Swedish context. The digital care model is able to provide services at approximately half of the cost of an in-person visit. Advantages may be particularly important in areas where geographic distances make traveling more time consuming and costly. Given the observed cost differences, scaling up the digital model would have the potential of generating substantial cost savings both from a societal perspective and a payer perspective. The risk of overall spending escalation would seem to be limited under these cost differences. More detailed analyses need to be done to arrive at more exact cost and outcome measures, including any quality-adjusted differences between the two models of primary care.

Acknowledgements Support with data collection by Jeremias Krugly and Daniel Persson of Min Doktor is gratefully acknowledged.

Author contribution The author alone designed the study, collected and analyzed the data, and wrote the final report.

\section{Compliance with ethical standards}

Data availability statement The datasets generated during and/or analyzed during the current study are available from the corresponding author on reasonable request.

Ethical standards The study did not require ethical clearance from the Swedish research ethical committee as no individual level data were collected.

Funding The study was funded by Min Doktor. Min Doktor provided the cost data for the digital model, but did not in any way influence the analysis, interpretation, or presentation of the results.

Conflict of interest Björn Ekman is an Associate professor at Lund University, Sweden. He declares no conflict of interest.

Open Access This article is distributed under the terms of the Creative Commons Attribution-NonCommercial 4.0 International License (http://creativecommons.org/licenses/by-nc/4.0/), which permits any noncommercial use, distribution, and reproduction in any medium, provided you give appropriate credit to the original author(s) and the source, provide a link to the Creative Commons license, and indicate if changes were made.

\section{References}

1. Hillestad R, Bigelow J, Bower A, Girosi F, Meili R, Scoville R, et al. Can electronic medical record systems transform health care? Potential health benefits, savings, and costs. Health Aff. 2005;24(5):1103-17.

2. Roman DH, Conlee KD. The digital revolution comes to US healthcare. New York: Goldman Sachs; 2015. 
3. European Commission. eHealth action plan 2012-2020: frequently asked questions. Memo /12/959 Brussels: The European Commission; 2012.

4. McKinsey \& Company. Värdet av digital teknik i den svenska vården (in Swedish: Value of digital technology in the Swedish health care system). Stockholm. 2016.

5. PWC. Digitala doktorn kan komma: Hur redo är Sverige för digital och virtuell vård? (in Swedish: The Digital Doctor: Is Sweden prepared for digital and virtual care?). Stockholm Price. 2015.

6. McDaid D. eHealth: what is the potential for better integration, delivery and cost effective care across Europe? ehealth week 2010 Barcelona March 2010 Barcelona: Administración pública at Ministerio de Sanidad, Política Social e Igualdad. Agencia de Calidad del SNS. 2010.

7. Ellis M, Cornford T, Moreno-Perez S. Why has there been very variable implementation of eHealth services within the EU? Eurohealth Int. 2015;21(4):20-3.

8. Kellerman AL, Jones SS. What it will take to achieve the as-yetunfulfilled promises of health information technology. Health Aff. 2013;32(1):63-8.

9. Fontenot SF. The affordable care act and electronic health care records: can technology help reduce the cost of health care? Physician Exec J. 2014;2014:68-72.

10. Brownlee S, Chalkidou K, Doust J, Elshaug AG, Glasziou P, Heath I, et al. Evidence for overuse of medical services around the world. Lancet. 2017;390(10090):156-68.

11. Dinesen B, Nonnecke B, Lindeman D, Toft E, Kidholm K, Jethwani K, et al. Personalized telehealth in the future: a global research agenda. J Med Internet Res. 2016;18(3):e53.

12. Darkins A. Telehealth services in the United States Department of Veterans Affairs (VA). Washington, DC: Veterans Health Administration; 2014.

13. Department of Health. Whole system demonstrator programme: headline findings. London: The Government of the UK; 2011.

14. Wade VA, Karnon J, Elshaug AG, Hiller JE. A systematic review of the economic analyses of telehealth services using real time video communication. BMC Health Serv Res. 2010;10(233).

15. Torre-Diez I, López-Coronado M, Vaca C, Aguado JS, Castro C. Cost-utility and cost-effectiveness studies of telemedicine, electronic, and mobile health systems in the literature: a systematic review. Telemed e-Health. 2015;21(2):81-5.

16. Anell A, Glenngård AH, Merkur S. Sweden-health system review. Copenhagen: The European Observatory on Health Systems and Policies; 2012 (contract no.: 5).

17. SKL. Statistik om hälso- och sjukvård samt regional utveckling 2015: Verksamhet och ekonomi i landsting och regioner Stockholm Sveriges Kommuner och Landsting. 2016.
18. Socialdepartementet (Department of Health). Effektiv vård (in Swedish: Effective care) Stockholm Svenska Regeringen (the Swedish Government). 2016.

19. Magnussen J, Vrangbaeck K, Saltman R, editors. Nordic health care systems: Recent reforms and current policy challenges. Birkshire: McGraw-Hill Education-Open University Press; 2009.

20. Ekman B, Wilkens J. A literature review of the regional implementation of the central Swedish government's health care reforms on choice and privatization. Health Econ Rev. 2015;5(1):39.

21. SKL. Patientavgifter (User-fees) Stockholm Sveriges Kommuner och Landsting various. https://skl.se/halsasjukvard/ patientinflytande/patientavgifter.246.html. Accessed $23 \mathrm{Feb}$ 2017.

22. SCB. Lönedatabasen (Wage database) Stockholm National Bureau of Statistics various. http://www.scb.se/sv_/Hittastatistik/Lonedatabasen/. Accessed 23 Feb 2017.

23. Vårdanalys. Vården ur primärvårdsläkarnas perspektiv - en jämförelse mellan Sverige och nio andra länder (in Swedish: Health care from the GP perspective-an international comparison). Stockholm Vårdanalys. 2015.

24. Riksrevisionen. Primärvårdens styrning-efter behov eller efterfrågan? (in Swedish: Primary care governance-need or demand?). Stockholm Riskrevisionen (Swedish National Audit Office). 2014.

25. Vårdanalys. Varierande väntan på vård: Analys och uppföljning av den nationella vårdgaranting (Follow-up of the national health care waiting guarantee). Stockholm Myndigheten för vård- och omsorgsanalys. 2015.

26. Min Doktor. Väntetider (Waiting times). Malmö: Min Doktor; 2016.

27. SKL. Väntetider i vården (Health care waiting times) Stockholm Sveriges Kommuner och Landsting various. http://www. vantetider.se/veta-mer/Vadmats-och-visas/Specialiserad-vard/. Accessed 23 Feb 2017.

28. Dullet NW, Geragthy EM, Kaufman T, Kissee JL, King J, Dharmar M, et al. Impact of a university-based outpatient telemedicine program on time savings, travel costs, and environmental pollutants. Value Health. 2017;20:542-6.

29. Kouskoukis M-N, Botsaris C. Cost-benefit analysis of telemedicine systems/units in greek remote areas. Phamacoecon Open. 2017;1:117-21.

30. Ashwood JS, Mehrotra A, Cowling D, Uscher-Pines L. Direct-toconsumer telehealth may increase access to care but does not decrease spending. Health Aff. 2017;36(3):485-91.

31. SKL. Bilaga 1: Beskrivning av indikatorer (Annex 1: description of indicators) Stockholm Sveriges Kommuner och Landsting. 2015 . 